\title{
Employment of the older generation
}

\section{SUMMARY}

In 2007 there were 20.7 million people aged 50 and over in the UK representing a 50 per cent increase from 1951. This article, using the Labour Force Survey of the UK, describes recent trends in the characteristics and labour market participation of older workers including: the employment rate of older workers and regional patterns; the influence of partners on labour market activity; the likely occupations, working patterns, employment status and qualifications of older workers; and the older generation gender pay gap.
his article examines trends in the labour market participation of older workers. Older workers are defined as people in employment who are aged 50 and over, which is consistent with the definition used by the Department of Business, Enterprise and Regulatory Reform (BERR) (see Hottop 2005). Other commonly used definitions include people aged between 50 and State Pension Age (SPA), and those aged between 50 and 69 which is applied by the Department for Work and Pensions (DWP) (see Irving, Steels and Hall, 2005). Where possible trends will be analysed using these definitions as well.

The period April to June 2008 is mainly used as the reference point for comparison with previous years because this is the last quarter before the contraction in the UK economy. Figures for October to December 2008 are also quoted to show that they do not change the conclusions of the analysis.

In 2007 there were 20.7 million people aged 50 and over in the UK. This is 50 per cent higher than the 1951 figure of 13.8 million. This increase and the associated change in the population structure has made the analysis of older workers an important issue because of the services demanded by this group. Furthermore, the decision to continue working or retire has important implications for the wider economy and the labour market.

As older workers leave the labour market, the composition of the labour supply can alter due to the removal of certain skills and experiences, which might influence the wages of the remaining workers. Of course, the composition of the labour market is also influenced by the numbers and characteristics of new entrants. For example, the composition of the labour force would change if more young people remain in full-time education for longer and therefore begin full-time work at a later stage.

The demographics of the labour market are therefore determined by the correspondence between outflows of older workers and inflows of younger (and other) workers. These inflows and outflows have important policy implications for taxation levels paid by the labour supply (either payas-your-earn (PAYE) or indirect taxes), and the numbers claiming their pension.

This article concentrates on the status of those people nearing SPA and the characteristics they exhibit, as presented by the Labour Force Survey (LFS). These LFS micro data have been weighted to the mid-2007 population estimates. However, there are a number of alternative data sources that can be used to analyse the characteristics of older workers as detailed in Box 1. In addition, data on pensions can be analysed from a number of sources such as the Family Resource Survey (carried out by DWP), administrative records from HM Revenue \& Customs (HMRC), and the Occupational Pension Scheme Survey (OPSS). These additional sources are not examined in this article. 
Box 1

\section{Sources of data on older workers}

\section{The Labour Force Survey (LFS)}

This is a quarterly survey using a sample of approximately 53,000 private address households in Great Britain and Northern Ireland. The survey requests information on respondents' personal circumstances and the labour market status during a specific reference period. Information is collected on respondents' personal characteristics as well as information about hours and earnings in main and second jobs.

\section{The Annual Survey of Hours and Earnings (ASHE)}

ASHE samples 0.8 per cent (1 per cent before 2007) of all employee jobs, taken from HM Revenue \& Customs pay-as-youearn (PAYE) records. Employers are asked to provide detailed information on the hours and earnings of their employees and on the workplace characteristics. Most information is derived from employers' pay records. ASHE provides accurate information on earnings, hours, and the characteristics of the employer, but asks very little information on personal characteristics.

\section{The English Longitudinal Study of Ageing (ELSA)}

ELSA is the first study in the UK to connect the full range of topics necessary to understand the economic, social, psychological and health elements of the ageing process. The aim is to explore the unfolding dynamic relationships between health, functioning, social networks and economic position of the older generation. It is also a study of people's quality of life as they age beyond 50 and of the factors associated with it. ELSA looks at the determinants of economic position in older age, the timing and circumstances of retirement and post-retirement labour market activity. More information on ELSA can be found at www.ifs.org.uk/elsa/

\section{Population}

Before explicitly analysing the labour supply it is useful to look at the demography of the population from which the workforce is drawn. The impact of a changing demographic picture on the wider economy can be explored using the old age dependency ratio which is the number of people aged above SPA as a proportion of people aged between 16 and SPA.

Although the number of people in older age groups in the UK population is increasing, Table 1 shows that the old age dependency ratio was close to 29 per cent in both April to June 1992 and the same quarter in 2000, before increasing to 30 per cent in 2008 . This is a product of the numbers of people of working age increasing at a similar rate to the numbers of people below 16 years of age and above SPA. The old age dependency ratio was still 30 per cent for the period October to December 2008.

A low old age dependency ratio can occur either because there is a small population of people over SPA or a large working age population. London has consistently had the lowest old age dependency ratio compared to other regions. ONS figures for internal migration (see ONS 2007) show that there have been net inflows of younger people moving to London, most likely related to finding employment, with the effect of increasing the working age population.

Wales and the South West have shown the highest old age dependency ratios for the years presented. This might reflect a large population of people aged above SPA with people moving to these regions after retirement or, alternatively, migration of younger workers away from the area. ONS figures for internal migration (see ONS 2007) show net inflows of older people moving to these regions, and further analysis confirms that Wales and the South West have the highest percentage of older people in all age groups. Therefore, high old age dependency ratios for these regions are a result of a large population aged above SPA. The composition of older people in all of the other regions is similar.

According to analysis by the Pensions Analysis Unit (PAU), the old age dependency ratio for the UK is expected to rise from 2006 (see ONS 2008a). The figures show that, in the absence of any increases in SPA, the old age dependency ratio was expected to reach 49 per cent by 2051 . But with increases in SPA taking place between 2010 and 2046 as a result of Government legislation, it is expected to fall back to 34 per cent in 2051 .

Table 1

\section{Old age dependency ratio by Government Office Region} (April to June each year)

\begin{tabular}{lccc}
\hline & 1992 & $\mathbf{2 0 0 0}$ & $\mathbf{2 0 0 8}$ \\
\hline London & 24.9 & 21.7 & 20.0 \\
Scotland & 27.9 & 28.8 & 30.4 \\
West Midlands & 28.5 & 29.5 & 31.3 \\
East Midlands & 28.8 & 29.2 & 30.6 \\
East of England & 29.1 & 30.2 & 32.4 \\
North West & 29.2 & 29.4 & 30.3 \\
North East & 29.2 & 30.2 & 31.1 \\
Yorkshire and the Humber & 29.3 & 29.6 & 29.6 \\
South East & 29.7 & 29.7 & 31.5 \\
Wales & 32.4 & 32.4 & 34.3 \\
South West & 34.6 & 34.6 & 36.3 \\
& & & 30.0 \\
GB & & 29.0 & \\
\hline
\end{tabular}

Note: Source: Labour Force Survey

1 The analysis does not include Northern Ireland because comparable data is not available for all periods presented
The employment rates of the older age dependents are of particular concern because increased participation in the labour market from people aged above SPA lowers the burden on the working age population. Table 2 shows that for the period April to June in 2008 the employment rates, in all regions, for people aged above SPA were higher than they were in 1992. However, for some regions the employment rate was lower in 2000 than in 1992.

The old age dependency ratio is a good indicator of the population structure, but the economic support ratio, defined as the number of people aged 16 and over in employment for every other person in the UK, will determine the economy's ability to deal with the pressure of an ageing population. This is because the UK operates a pay-as-you-go (PAYG) state pension scheme where taxes paid by current 
Table 2

\section{Employment rates of people aged above SPA by Government Office Region (April to June each year)}

\begin{tabular}{lrrr}
\hline & 1992 & $\mathbf{2 0 0 0}$ & $\mathbf{2 0 0 8}$ \\
\hline North East & 5.0 & 5.3 & 9.6 \\
North West & 6.6 & 6.5 & 9.8 \\
Yorkshire and the Humber & 6.3 & 7.0 & 10.7 \\
East Midlands & 7.5 & 7.8 & 10.7 \\
West Midlands & 8.5 & 7.6 & 11.4 \\
East of England & 9.6 & 9.7 & 13.4 \\
London & 8.5 & 10.2 & 13.6 \\
South East & 11.0 & 10.2 & 14.3 \\
South West & 8.3 & 8.7 & 12.6 \\
Wales & 7.6 & 5.7 & 10.7 \\
Scotland & 7.5 & 6.4 & 9.7 \\
& & & 11.8 \\
\hline GB & 8.1 & 8.1 & \\
\hline
\end{tabular}

\section{Note:}

Source: Labour Force Survey

1 The analysis does not include Northern Ireland because comparable data is not available for all periods presented

workers fund the state pensions of current pensioners. A fall in the economic support ratio as projected by ONS (see ONS 2008b) would mean there are proportionately fewer workers to support the system.

\section{Employment}

Employment rates are used to compare employment patterns among different population groups. This shows the number of people in employment for a given population group as a proportion of the total population of that group. The employment rate of older people gives an insight into the labour market activity of this group. The importance of encouraging economic activity is emphasised by the fact the UK Government has introduced several measures to enable people to work later in life and save more for retirement including the Pensions Act (1995), the Pensions Act (2007) and the Employment Equality (Age) Regulations (2006). These pieces of legislation resulted in the raising of the SPA for men and women to 68 by 2046 and gave employees the right not to retire at 65 . The Government's commitment to Public Service Agreement 17, to tackle poverty and promote greater independence and wellbeing in later life (see HM Treasury 2007), explicitly recognises the employment rate of those aged between 50 and 69 as one of the key indicators of progress against this target.

Figure 1 shows that, based on the same three-month period of April to June each year, all older worker employment rates have increased between 1992 and 2008. The employment rate for all workers (aged 16 and over) increased by 3.2 percentage points from 56.9 to 60.1 . The employment rates of those aged 50 and over and those aged between 50 and SPA have shown comparatively larger increases of 7.4 and 8.8 percentage points respectively. The increases in older worker employment rates compared with 16 years ago show the differences in labour market outcomes and participation according to age. This is perhaps more apparent when comparing the top two lines in Figure 1, which show that for April to June over the period 1992 to 2008 the gap between the working age (16-59/64) and 50-SPA employment rates has narrowed from 7.8 to 2.5 percentage points, implying increases in employment for younger workers have not been as great as those increases for older workers. The figures for October to December 2008 show that employment rates have fallen, compared with the same quarter a year previous, for all groups presented except for those aged 50 and over.

As Figure 2 shows, there are regional variations in the employment rate of older people. Comparing the April to June period for the three years of 1992, 2000 and 2008, the employment rates for those aged over
50 increased for all regions. The largest increases between 1992 and 2008 were for the North East (9.7 percentage points) and South West (8.7 percentage points). In 2008 the employment rate for those aged 50 and over was highest for the South East (42.7 per cent) and lowest for North East (34.1 per cent). The same trends are observed when using the figures for October to December 2008.

When looking at the employment rates for those aged 50 to SPA, analysis shows the same trends are observed as for the rates for those aged 50 and over. Figure 3 shows the employment rates of people aged between SPA and 69 by region for the April to June period for the years 1992, 2000 and 2008. The employment rates have increased for all regions over the period 1992 to 2008 with the largest increases occurring during the period 2000 to 2008.

The employment rate for people aged between SPA and 69 in London showed the largest percentage point increase over the April to June period, rising from 16.7 in 1992 to 28.8 in 2008 an increase of 12.1 percentage points. However, using figures for October to December for the years 1992 and 2008, London does not have the largest increase in the employment rate.

The employment rates for people aged between SPA and 69 more than doubled for people living in the North East, rising from 8.5 per cent to 20.1 per cent over the April to June period for the years 1992 to 2008. For the North East this equated to the number of people in employment increasing from 17,000 in 1992 to 40,000 in 2008.

This analysis has demonstrated that more people are working beyond SPA, which currently runs to 65 for men. Further analysis by gender and working patterns will give an insight into the main drivers behind this increase.
Figure 1

Employment rates of older workers (April to June each year)

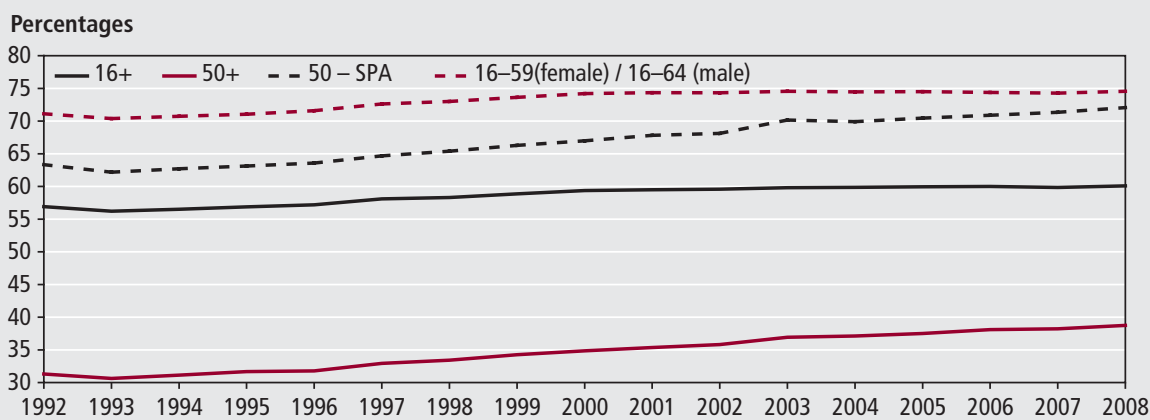




\section{Figure 2 \\ Employment rates of people aged 50 and over (April to June each year)}

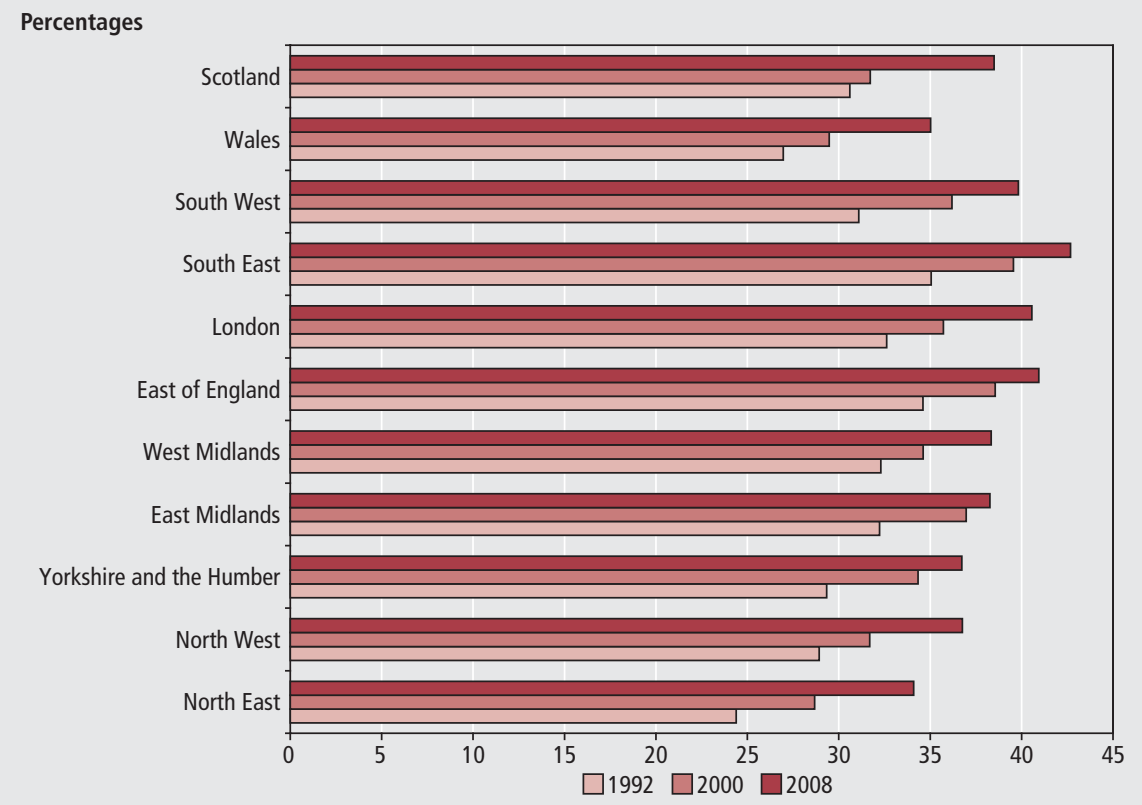

Note:

Source: Labour Force Survey

The analysis does not include Northern Ireland because comparable data is not available for all periods

\section{Figure 3 \\ Employment rates of people aged between SPA and 69 by region (April to June each year)}

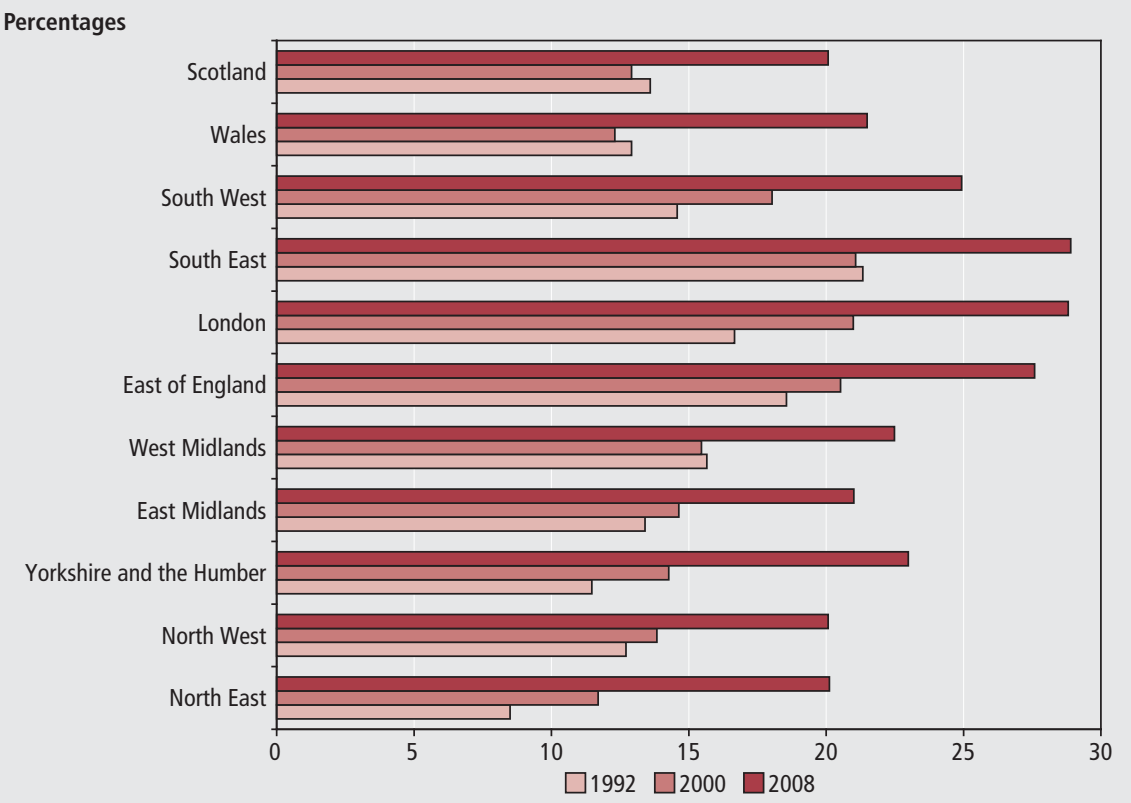

Note:

Source: Labour Force Survey

The analysis does not include Northern Ireland because comparable data is not available for all periods

Figure 4 shows patterns of economic activity by age and, as expected, the employment rate falls and the inactivity rate rises as men approach SPA. The employment rate of men aged 25-49 in April to June 2008 was 88.7 per cent, compared with 58.4 per cent for the 60-64 age group. In contrast, the economic inactivity rate for men in the 25-49 age group was 7.5 per cent, rising to 39.9 per cent for men aged 65-69. The largest absolute difference in the inactivity rate between age groups is between 60-64 and 65-69 years, where the inactivity rate is 38 percentage points higher in the older age group, reflecting the existing SPA. The patterns are broadly similar for women. The figures for October to December 2008 show that the employment rate for men aged 60-64 was
58 per cent and the same trends as above are observed.

\section{Influence of partners on labour market participation}

A partner's economic status can influence someone's decision to work for economic or social reasons. This may simply be because of the need to consider another person's preferences for time use, or because of added responsibilities. However, the social reasons can be subtly different for older workers than for younger workers. This can be analysed using the household LFS dataset. Analysis is conducted at the family unit and household levels from these data, and also for person-level analyses to ascertain the characteristics of the family unit or household in which people live. In the household datasets a head of household is identified, which has been used to distinguish between partners with different labour market outcomes.

Figure 5 shows the labour market situation of couples where both are aged 50 and over. It can be seen that the status of a partner is correlated with an older person's participation in the labour market. Banks and Tetlow (2008), using ELSA, show evidence of complementarities in leisure among couples.

In the period April to June 2008 over three quarters (77 per cent) of married and cohabiting couples who were both aged 50 and over had the same economic status as their partner. So if one partner was working in they were most likely to have a working partner. By the same token, if one partner was inactive they were most likely to have an inactive partner. This figure of 77 per cent can be further divided to show that 35 per cent were working couples (with both partners in employment), and 42 per cent were workless couples (where both were either unemployed or inactive).

Over the April to June period for the years 1992 to 2008, for couples aged 50 and over, there was a 3.5 percentage points fall in the proportion of couples where both partners were inactive and an equal rise for couples where both partners worked.

Where both partners were over SPA the most likely outcome was for both to be unemployed or inactive (over 83 per cent). There are some differences in labour market participation of couples when the head of family is below SPA and partner is above, and also when the head of family is above SPA and the partner is below. Both partners were more likely to be working when the head of family was below SPA, 


\section{Figure 4}

\section{Economic activity and inactivity of men by age (April to June 2008)}

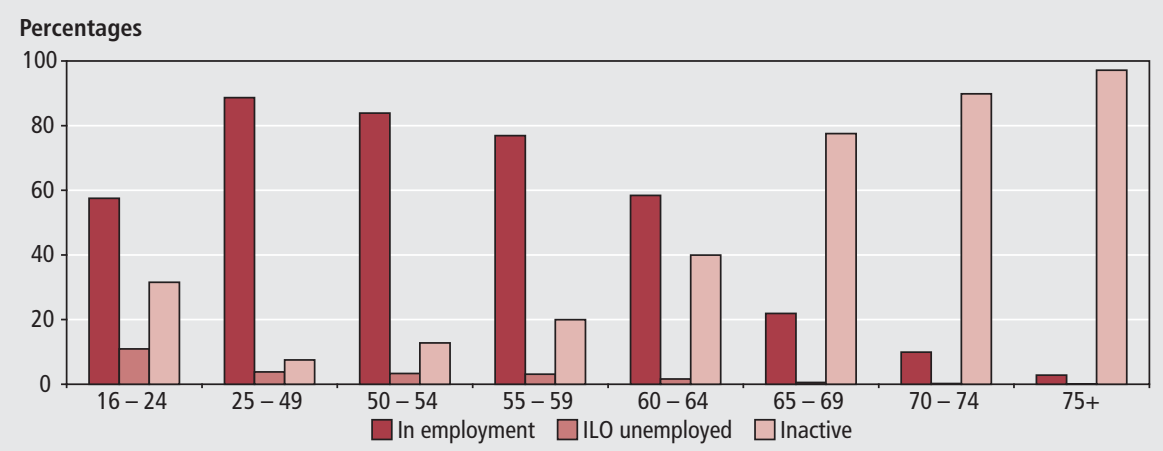

Source: Labour Force Survey

\section{Figure 5}

Labour market situation of couples (April to June each year)

Percentages

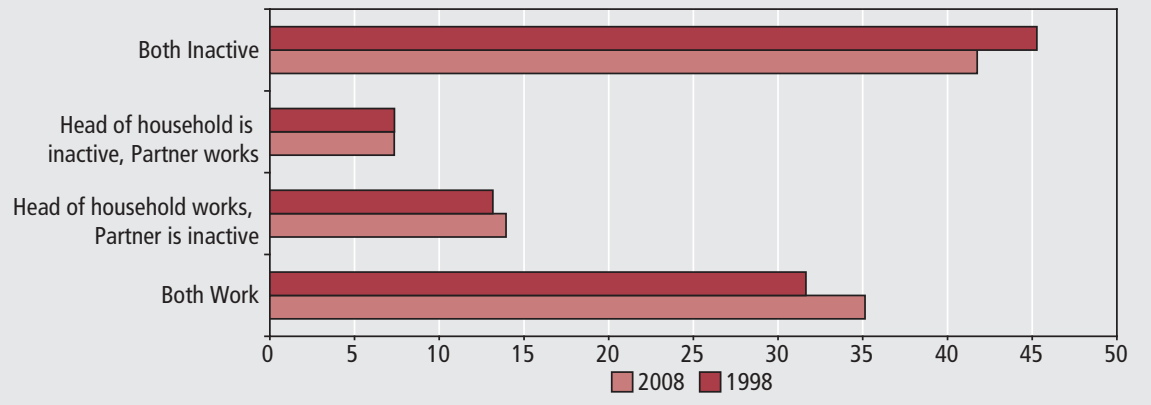

Source: Household Labour Force Survey

at 25 per cent, compared with 22 per cent when the head of family was above SPA. Likewise, both partners were more likely to be inactive when the head of family was above SPA, at 41 per cent, compared with 30 per cent when the head of family was below SPA.

\section{Marital status}

As outlined previously the marital/ cohabiting status of couples has important social implications because decision making needs to take account of a second person.

Figure 6 shows the employment rates of the older generation by marital status. It can be seen that older people who were married or cohabiting were more likely to be in employment than people without a partner. In the three months to June 2008, the employment rate among people aged 50-54 who were married or cohabiting was 84 per cent compared with 70 per cent of people in the same age group without a partner. This trend was evident across all the older age groups. The employment rates are slightly lower but the same trends are observed when using the figures for October to December 2008.

Comparisons carried out by ONS show that employment rates for older workers are similar in ELSA to the results produced
(April to June period). In the same period employment of people aged over 50 increased by 1.1 million, of which 500,000 were aged above SPA.

Over the period 2001 to 2008 , there was an increase in the numbers of working people aged between 50 and SPA in all occupations except Administration and Secretarial; Process, Plant and Machine Operatives; and Elementary Occupations. The largest increase was in Professional Occupations, with 225,000 more older workers in these occupations in 2008 than there were in 2001.

There were also more people aged above SPA employed in all occupations in 2008 compared to 2001 . The largest increases were for people working in the Administration and Secretarial and the Associate Professional and Technical occupations with increases of 92,000 and 86,000 respectively. The jobs that were most likely to be carried out by those aged above SPA were Administration, Secretarial, Health Associate and Public Services.

\section{Working patterns}

Over the period 1992 to 2008, numbers of older workers have increased coinciding with the changing demographic profile and improvements in healthcare. Figures from the LFS, and Banks and Tetlow (2008) based on ELSA, both show that there have been larger absolute increases in full-time working. The working patterns of the older generation / cohorts have been stable with the proportions working full-time and parttime remaining at 69 per cent and 31 per cent respectively.

When conducting a breakdown by age bands a similar picture emerges with most groups showing larger increases for full-time working. However, in the three months to 2008 there were approximately 350,000 more people working full-time and
There were 1.8 million more people in employment in 2008 than in 2001
Figure 6

Employment rates of older people by martial status and age (April to June 2008)

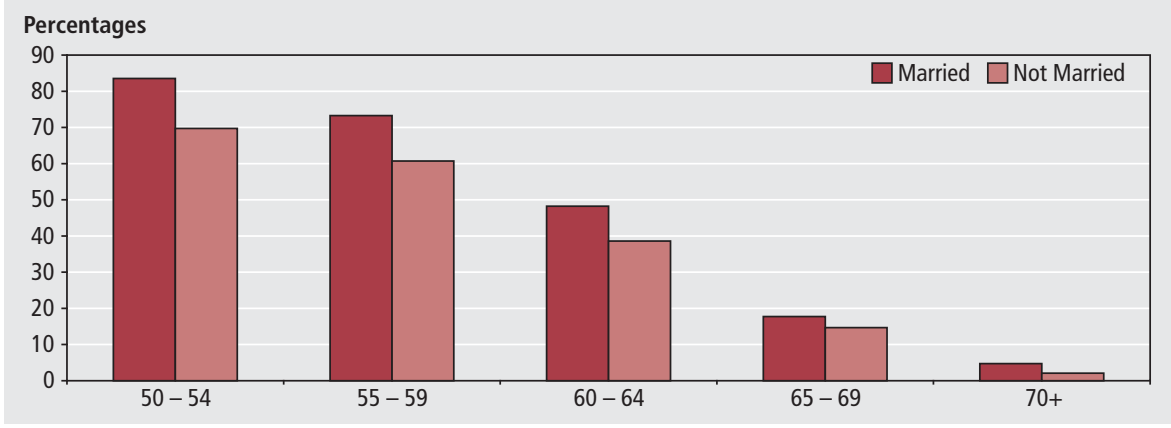

Source: Labour Force Survey, not seasonally adjusted 
350,000 more people working part-time aged 60 to 64 compared to 1992 . Although the absolute increase is the same, in relative terms the increase in part-time workers for this age group is larger than for full-time workers.

In 2008, there were more women working full-time (51 per cent) compared to 1992 (42 per cent), the largest contributors to the increase were those aged 50 to 54 and 55 to 59 .

\section{Employment status}

The employment status of the workforce varies with age and sex. In April to June 2008, although most workers in each age group were employees, self-employment was more common among older workers than among the younger age groups. This is shown by the fact that 18 per cent of people aged 50 and over were self-employed compared with 12 per cent of people aged 25 to 49 . Older men were more likely than older women to be self employed - 25 per cent of men aged 50 and over compared with 11 per cent for women. Gender differences in self-employment become even more marked after SPA. 40 per cent of men aged 65 and over were self-employed compared with 13 per cent of women aged 60 to 64 in 2008 . The figures for October to December 2008 show that 19 per cent of people aged 50 and over were self-employed compared with 12 per cent of people aged 25 to 49 .

\section{Qualifications}

The level of qualifications held by individuals influences their labour market outcomes regardless of age. In 2008, people aged 50 to SPA with qualifications had an employment rate of 77.1 per cent compared with 50.9 per cent for those with no qualifications. The inactivity rate for people aged 50 to SPA with no qualifications was 46.6 per cent compared with 20.6 per cent for those with qualifications. The main reasons for a high inactivity rate for people aged 50 to SPA with no qualifications were: not looking for work due to long term sickness/disability and looking after family, and would like to work but not seeking due to long term sickness or disability. The same trends are observed when using the figures for October to December 2008.

\section{Older generation gender pay gap}

The gender pay gap is a measure of the difference between the earnings of men and women. It is determined by calculating women's average pay as a percentage of men's. So, for example, the gender pay gap

Figure 7

\section{Gender Pay Gap for Full time employees by age (April to June each year)}

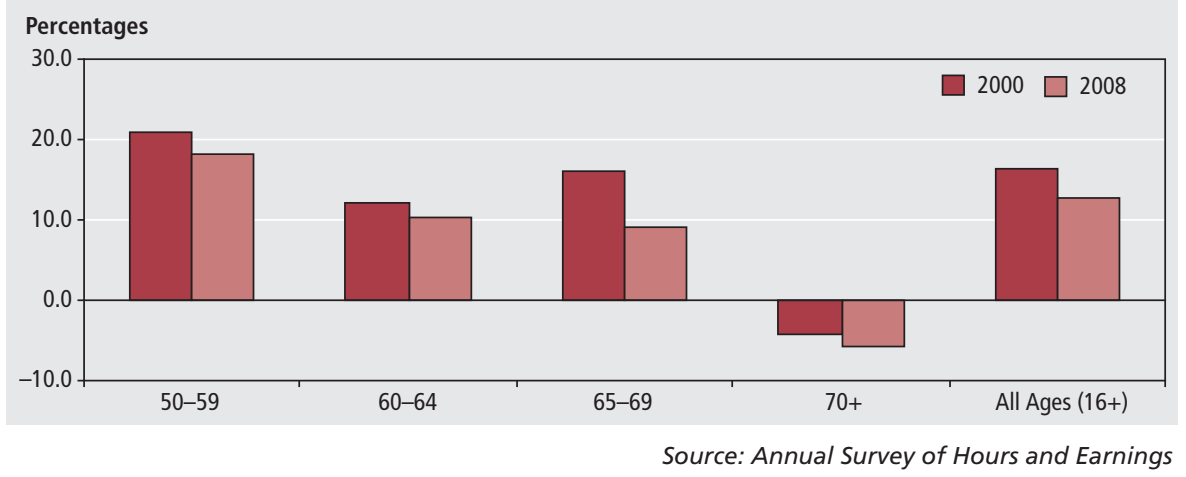

would be 15 per cent if women's pay is 85 per cent of men's pay. This section examines how the difference between the average earnings of men and women changes as they approach SPA and beyond. To be consistent with other releases, the median earnings for full-time employees is used as the basis for comparison, however, a similar picture emerges when the earnings of parttime employees are also included and the gender pay gap is analysed using median earnings for all employees.

Figure 7 shows the gender pay gap by age band compared with all employees aged 16 and over. In the three months to June 2008 , the median hourly earnings of full-time male employees was $£ 12.50$ compared with $£ 10.91$ for women resulting in a gender pay gap of 12.8 per cent. There has been a 21 per cent reduction in the overall gender pay gap since 2000 when it stood at 16.3 per cent.

Figure 7 also shows that the gender pay gap for older full-time employees for all the older age groups has narrowed over the April to June period for the years 2000 to 2008 in line with the trend for all full-time employees. The largest reduction in the gender pay gap over this period was for employees aged 65-69 where it narrowed from 16.5 per cent to 9.6 per cent, a 42 per cent reduction. In 2008, the median hourly earnings of male full-time employees aged 65-69 was $£ 8.92$ compared with $£ 7.51$ for female employees of the same age.

In 2008, the gender pay gap for full-time employees aged 50-59 was 18.2 per cent compared with 21 per cent in 2000. For employees aged 60-64 it narrowed from 12.2 per cent in 2000 to 10.3 per cent in 2008. The figures for those aged 70 and over show that full-time female employees earn more than men and that the gap has increased over the period 2000 to 2008 . However, the sample size for these groups is very small and the estimates do fluctuate from year to year.

\section{Retirement}

The age at which people retire is difficult to estimate, in part because older people who have become economically inactive may give different reasons for their inactivity such as retirement, ill-health or the inability to find suitable work even though their situations are the same.

The LFS and ASHE surveys both have limitations when trying to estimate the number of retirees because people can leave the labour market and re-enter later in life. For example, someone can retire from one profession and re-enter the labour market in a different industry or occupation. In addition, it is difficult to track people who retire from employment and become self-employed, for example work as a consultant or run their own business. And not everyone retires at SPA because they have different personal and economic circumstances.

ONS has devised a method for looking at when older people withdraw from the labour market (see Wild 2006). Figures published by ONS based on the LFS (see ONS 2008b) show that for April to June 2008 , the average age at which workers over 50 retired reached its highest level for men (64.6 years) since 1984, when data were first available. For women comparable figures showed an increase from 60.7 in 1984 to 61.9 in 2008.

\section{Conclusion}

This article has presented the employment characteristics of the older generation given the backdrop of an ageing population. Employment rates have increased for all workers across the UK, but the group of people aged between 50 and SPA has shown the largest increase. In addition, the 
increase in employment for older workers has been greater than that of younger workers. However, the LFS shows that there are regional disparities in the employment rates, dependency ratios, and the age composition of workers.

The analysis carried out in this article shows that for older workers a partner is particularly important in determining the economic status of a person. More than three quarters of couples who were both aged over 50 had the same economic status as their partner. This influence was further underlined by the fact that older people who were married or cohabiting were more likely to be in employment than those with no partner.

\section{CONTACT}

(《)elmr@ons.gsi.gov.uk

\section{REFERENCES}

Banks J and Tetlow G (2008) 'Extending Working Lives', in J Banks, E Breeze, C Lessof and J Nazroo (eds), Living in the 21st century: older people in England, The 2006 English Longitudinal Study of Ageing, Institute for Fiscal Studies

HM Treasury (2007) 'Pre-Budget Report and Comprehensive Spending Review 2007', The Stationery Office, London and at: www.hm-treasury.gov.uk/pbr_csr07_ repindex.htm

Hotopp U (2005) 'The Employment Rate of Older Workers', Labour Market Trends February 2005 and at:

www.statistics.gov.uk/articles/Labour_ market_trends/employment_rate_old_ workers.pdf

Irving P, Steels J and Hall N (2005) 'Factors affecting the labour market participation of older workers: Qualitative research', Department for Work and Pensions Research Report no. 281 and at: www.dwp.gov.uk/asd/asd5/rports20052006/rrep281.pdf
Office for National Statistics (2007) 'Internal Migration by Local Authorities in England and Wales', available at:

www.statistics.gov.uk/STATBASE/Product. asp?vInk=15148

Office for National Statistics (2008a)

'Population Change', Pension Trends 2008, Chapter 2 and at: www.statistics.gov.uk/downloads/theme_ compendia/pensiontrends/Pension_Trends_ ch02.pdf

Office for National Statistics (2008b) 'The Labour Market and Retirement', Pension Trends 2008, Chapter 3 and at:

www.statistics.gov.uk/downloads/theme compendia/pensiontrends/Pension_Trends_ ch03.pdf

Wild R (2006) 'Estimating he average age of withdrawal from the Labour Force' available at: www.statistics.gov.uk/cci/article. asp? id $=1669$ 